\title{
House dust mite allergens mediate the activation of c-kit in dendritic cells via Toll-like receptor 2
}

\author{
WEI WU ${ }^{1}$, CHUN-XIA WANG $^{2}$, HUI CHEN ${ }^{1}$, JING ZHOU $^{1}$, JIN-ZHAO ZHANG ${ }^{1}$, \\ $\mathrm{LIN} \mathrm{GAO}^{1}$ and HONG-YAN ZHOU ${ }^{1}$ \\ ${ }^{1}$ Department of Respiratory and Critical Care Medicine, The Affiliated Hospital of Xi'an Medical University, Xi'an, Shaanxi 710077; \\ ${ }^{2}$ Department of Medicine, Baoji Vocational and Technical College, Baoji, Shaanxi 721000, P.R. China
}

Received October 15, 2014; Accepted June 18, 2015

DOI: $10.3892 / \mathrm{mmr} .2015 .4092$

\begin{abstract}
Several studies have demonstrated that the c-kit proto-oncogene and its ligand, stem cell factor, are important in the development of asthma. House dust mite (HDM; Dermatophagoides pteronyssinus) allergens are a major trigger in the development and exacerbation of asthma. HDM allergens can induce the activation of c-kit in dendritic cells (DCs), leading to the development of allergic asthma. Previous studies have demonstrated that activation of Toll-like receptor 2 (TLR2) evokes a T helper (Th)2 immune response and promotes experimental asthma. The aim of the present study was to assess whether HDM mediates the activation of c-kit in DCs via TLR2. Monocyte-derived DCs were generated from C57BL/6 mice, and cultured with interleukin (IL)-4 and granulocyte-macrophage colony-stimulating factor. The DCs were then sensitized with HDM $(10 \mu \mathrm{g} / \mathrm{ml})$ for $72 \mathrm{~h}$. TLR2-specific small interfering (si)RNA was used to silence and inhibit the expression of TLR2 in the DCs. The expression levels of c-kit and B7 (CD80/CD86) were measured, by analyzing the DC culture supernatant for the presence of IL-6 and IL-12. Inhibition of TLR2 using specific siRNA downregulated the expression of c-kit in the HDM-activated DCs. In addition, silencing of TLR2 inhibited the expression of CD80/CD86, decreased the production of IL-6, and increased the production of IL-12. These results indicated that TRL2 are important in the activation of c-kit by HDM in DCs.
\end{abstract}

\section{Introduction}

Asthma is a chronic bronchial disease characterized by bronchial hyper-responsiveness (AHR) and airway inflammation on exposure to various stimuli. House dust mites (HDM) are

Correspondence to: Dr Wei Wu, Department of Respiratory and Critical Care Medicine, The Affiliated Hospital of Xi'an Medical University, 48 West Fenghao Road, Xi'an, Shaanxi 710077, P.R. China E-mail:wwatp@163.com

Key words: house dust mite, Toll-like receptor 2, c-kit, small interfering RNA one of the most common and most potent allergens that trigger asthma, and $\sim 60-100 \%$ of asthmatics are sensitized to HDM allergens (1); therefore, HDM allergens are considered one of the most important asthma-inducing allergens.

The c-kit proto-oncogene is a member of the tyrosine kinase receptor family, which is encoded at the white spotting locus and binds to the ligand, stem cell factor (SCF). c-kit is critical for the proliferation, survival and differentiation of hematopoietic stem cells and progenitor cells (2). Previous studies have focused on the c-kit-induced differentiation of mast cells and the production of inflammatory cytokines, including histamine and leukotriene $(3,4)$.

Immune responses against invading pathogens are initiated by Toll-like receptors (TLRs), which recognize distinct, structurally conserved, pathogenic components. The HDM, Dermatophagoides pteronyssinus, is a common source of indoor allergens, and $\sim 10 \%$ of individuals with asthma suffer from HDM-mediated allergy $(5,6)$. TLR-dependent activation of antigen-presenting cells (APCs) leads to the processing and presentation of antigens to $\mathrm{CD} 4^{+} \mathrm{T}$-cells, steering the inflammatory response towards a $\mathrm{T}$ helper (Th)2-mediated response pathway (7). Dendritic cells (DCs) are efficient APCs, which are important in the pathogenesis of allergic asthma. DCs present the HDM allergens, which are subsequently taken up and processed by Th2 cells, leading to Th2 cell activation. Activated Th2 cells produce various cytokines, including interleukin (IL)-4, IL-5 and IL-13, which are involved in the recruitment of eosinophils, goblet cell hyperplasia and in AHR (8). A previous study demonstrated that the activation of TLR 2 evokes a Th2 immune response and promotes experimental asthma, indicating that TLR 2 can induce an asthmatic inflammatory response (9). In addition, HDM can promote cell surface expression of c-kit when bound to its ligand on DCs, which can prime naive CD4 ${ }^{+} \mathrm{T}$-cells toward Th2 and Th17 responses (10). Based on these previous findings, the present study aimed to investigate whether the c-kit receptor is activated by HDM via TLR2 in DCs.

\section{Materials and methods}

Animals. Specific-pathogen-free (SPF)-grade male C57BL/6 mice (6-8 week-old; 20-25 g), were purchased from the Laboratory Animal Center of the Fourth Military Medical 
University (Xi'an, China). The experimental procedures were approved by the ethics committee of the Affiliated Hospital of Xi'an Medical University (Xi'an, China).

Generation and culture of monocyte-derived DCs. The DCs were prepared from bone marrow progenitors, as described in previous studies $(11,12)$. The $\mathrm{C} 57 \mathrm{BL} / 6$ mice were housed in a temperature $\left(22 \pm 2^{\circ} \mathrm{C}\right)$ and humidity $(60 \pm 5 \%)$ controlled environment, under a $12 \mathrm{~h}$ light/dark cycle, with $24 \mathrm{~h}$ ad libitum access to standard Purina (5001) rodent chow (autoclaved) and tap water, which was heated to boiling point for $20 \mathrm{~min}$ and cooled to room temperature before use. The mice were anesthetized intraperitoneally with $3 \mathrm{ml} / \mathrm{kg}^{-1}$ chloral hydrate (Sinochem Qingdao Co., Ltd., Qingdao, China), and sacrificed by exsanguination from the abdominal aorta after $24 \mathrm{~h}$. The femurs and tibiae of the male C57BL/6 mice (8-12 weeks old) were removed and purified from the surrounding muscle tissues by rubbing with paper tissues. The bone marrow cells were flushed from the femurs and tibiae of the mice, washed and cultured in 6 -well plates $\left(2 \times 10^{6}\right.$ cells $\left./ \mathrm{ml}\right)$ containing $4 \mathrm{ml}$ complete medium (RPMI 1640; Invitrogen Life Technologies; Carlsbad, CA, USA). The medium was supplemented with $2 \mathrm{mM}$ L-glutamine, $100 \mathrm{U} / \mathrm{ml}$ penicillin, $100 \mu \mathrm{g}$ streptomycin, $50 \mu \mathrm{M}$ 2-medroxyestradiol, and $10 \%$ fetal calf serum (FCS), obtained from Invitrogen Life Technologies, which contained recombinant granulocyte-macrophage colony-stimulating factor (GM-CSF; $10 \mathrm{ng} / \mathrm{ml}$; R\&D Systems, Inc., Minneapolis, MN, USA) and recombinant mouse IL-4 (10 ng/ml; R\&D systems). All cell cultures were incubated at $37^{\circ} \mathrm{C}$ in a humidified atmosphere containing $5 \%$ $\mathrm{CO}_{2}$.

TLR2-specific silencing in vitro. The DCs were cultured in specific conditions, as described above. On day 6 , the immature DCs were harvested, suspended in $200 \mu 1$ serum-free RPMI 1640 and aliquoted into a 24-well plate (Invitrogen Life Technologies). A total of $1 \mu \mathrm{g}$ of each TLR2 small interfering (si)RNA (Qiagen, Hilden, Germany; sense 5'-GACUUAUCCUAUAAUUACUTT-3' and antisense 5'-AGUAAUUAUAGGAUAAGUCTA-3') and negative control (scrambled) siRNA (sense 5'-UAGGCGCAGCUCCGGAUCGDTT-3' and antisense 5'-CGAUCCGGAGCUGCGCCUADTT-3') were incubated separately, with $5 \mu 1$ Lipofectamine (Genlantis, Inc., San Diego, CA, USA) in $100 \mu 1$ serum-free RPMI 1640 at room temperature for $5 \mathrm{~min}$. The TLR2-specific and control siRNA mixtures were then added to respective $200 \mu \mathrm{l}$ DC cell cultures. Following $4 \mathrm{~h}$ incubation at $37^{\circ} \mathrm{C}$, an equal volume of $200 \mu$ l RPMI 1640 supplemented with 20\% FCS was added to the cells. On day 7, the DCs were stimulated with the HDM allergens $(10 \mathrm{mg} / \mathrm{ml})$ and incubated for $24 \mathrm{~h}$. The expression of CD117 in the DCs was determined using flow cytometry on day 8 . The siRNA transfection and silencing of the expression of TLR2 in DCs was performed according to the methods described in a previous study (13).

Sensitizing DCs with HDM. A purified antigen of HDM extract from the D. pteronyssinus allergen (Peking Union Laboratories, Beijing, China), containing a known concentration of Der p 1, was used in the experiments of the present study. The doses of HDM correspond to the quantity of Der p 1 used. The DCs were collected and cultured, as described above. They were then treated with HDM $(10 \mu \mathrm{g} / \mathrm{ml})$ and co-cultured for $72 \mathrm{~h}$ at $37^{\circ} \mathrm{C}$.

Flow cytometry. Flow cytometric analysis was performed to examine the variation in the expression of CD117 in the DCs, for verification of the effects of TLR2-specific siRNA on the expression of c-kit. The cells were filtered through $20 \mu \mathrm{m}$ nylon mesh (BD Biosciences, San Jose, CA, USA), and $10^{6}$ cells were incubated with monoclonal antibodies targeting CD117 (cat. no. MAB332; R\&D Systems, Inc.). Following staining, the cells were analyzed by flow cytometry using a FACSCalibur with CellQuest version 5.1 software (BD Biosciences).

Reverse transcription-quantitative polymerase chain reaction (RT-qPCR). Total RNA was isolated from the mature DCs, which were collected $72 \mathrm{~h}$ following siRNA-TRL2 transfection, using RNeasy Mini kits (Qiagen, Valencia, CA, USA) containing TRIzol reagent for extraction (Gibco Life Technologies, Carlsbad, CA, USA). The total RNA was then reverse transcribed into cDNA using a reverse transcriptase kit at $50^{\circ} \mathrm{C}$ for $30 \mathrm{~min}$. The cDNA was amplified using a Promega PCR Single-Step kit (Promega Corporation, Madison, WI, USA), according to the manufacturer's instructions. The following primers (Invitrogen Life Technologies) were used: TLR2, sense 5'-ATCAGCAGGAACAGAGCACA-3' and antisense 5'-AGGAGCAGCAAGCAC-3'; c-kit, sense 5'-ACCCACAGGTGTCCAATTATTC-3', antisense 5'-TGGCGTTCATAATTGAAGTCAC-3'; $\beta$-actin, sense 5'-CCTCATGAAGATCCTGACCG-3', and antisense 5'-ACCGCTCATTGCCGATAGTG-3'. $\beta$-actin served as the internal control. Quantification of PCR products was carried out using the FTC-2000 (Shanghai Funglyn Biotech Co., Ltd., Shanghai, China). The threshold cycle (Ct) of each sample was recorded as a quantitative measure of the amount of PCR product in the sample. Relative changes in expression levels were calculated using the $2^{-\Delta \Delta \mathrm{CT}}$ method (14).

Western blotting. The DCs were collected $72 \mathrm{~h}$ following siRNA-TRL2 transfection. Total protein was extracted using ice-cold radioimmunoprecipitation lysis buffer (Santa Cruz, Biotechnology, Inc., Dallas, TX, USA). The protein concentrations were quantified using the Bradford method (Quick Start ${ }^{\mathrm{TM}}$; Bio-Rad, Hercules, CA, USA). Cytoplasmic protein samples $(20 \mu \mathrm{g})$ were separated by $15 \%$ SDS-PAGE and semi-dry transferred onto polyvinylidene difluoride membranes (EMD Millipore, Billerica, MA, USA). The membranes were blocked for $1 \mathrm{~h}$ at room temperature with 5\% bovine serum albumin (Santa Cruz, Biotechnology, Inc.). The blots were then incubated at $4^{\circ} \mathrm{C}$ overnight with the following primary antibodies: Anti-TLR2 (sc-12507), anti-c-kit (sc-1494) and anti-GAPDH (2118S) (Santa Cruz Biotechnology, Inc.), at a 1:1,000 dilution in Tris-buffered saline with Tween 20 (TBST). GAPDH was used as a loading control. The blots were washed in TBST and then incubated with an anti-rabbit immunoglobulin G-horseradish peroxidase-conjugated secondary antibody (1:20,000 dilution in TBST; Pierce Biotechnology, Inc., Rockford, IL, USA) for 
A

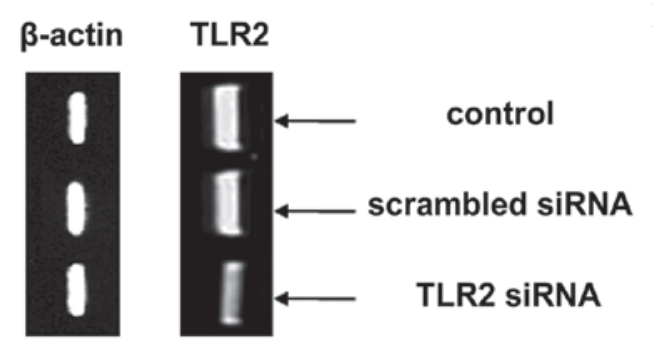

C

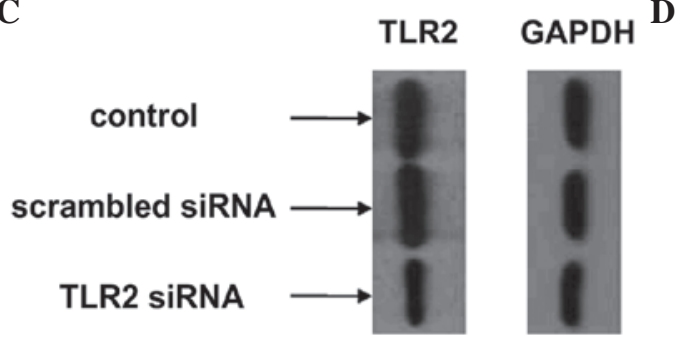

B
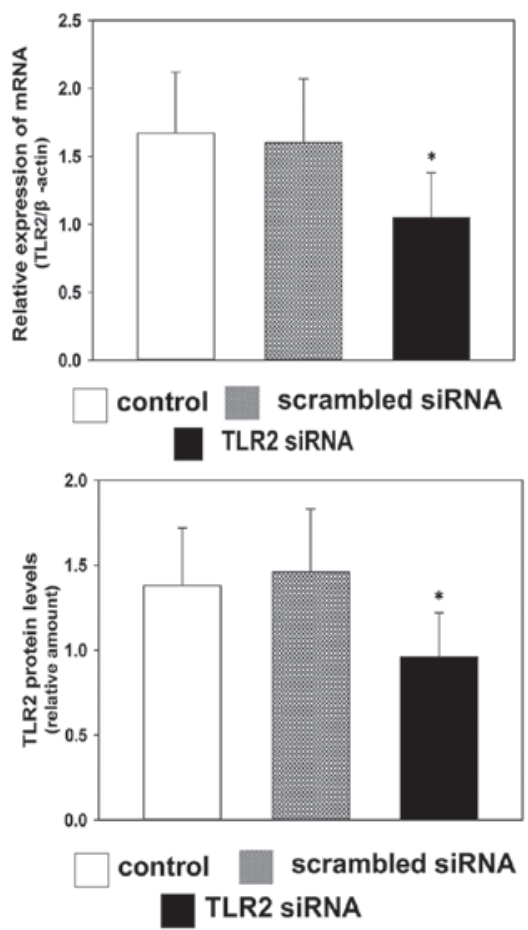

Figure 1. Representative analysis of mRNA and protein expression levels of TLR2in DCs. (A) mRNA expression levels of TLR2 were downregulated 72 h post-transfection in the TLR2-siRNA group. (B) Data are presented as the mean \pm SD of the relative intensity of TLR2 normalized against $\beta$-actin. (C) Protein expression levels of TLR2 in DCs $72 \mathrm{~h}$ post-transfection in the TLR2-siRNA group. (D) Data are presented as the mean \pm SD of the relative intensity of TLR2 normalized against GAPDH. ${ }^{*} \mathrm{P}<0.05$, vs. control and scrambled-siRNA groups. The experiment was performed three times and representative results are presented. TLR2, Toll-like receptor; DCs, dendritic cells; siRNA, small interfering RNA; SD, standard deviation.

$1 \mathrm{~h}$ at room temperature. After further washing with TBST the blots were visualized using enhanced chemiluminescence (GE Healthcare Life Sciences, Little Chalfont, UK) and densitometrically quantified using a Western Blotting Detection system (GE Healthcare Life Sciences). All results were normalized to GAPDH. Heat-induced epitope retrieval was conducted.

ELISA. The levels of inflammatory cytokines in the DC culture supernatants were analyzed using ELISA, with ELISA kits for IL-6 and IL-12 (R\&D Systems, Inc.), according to the manufacturer's instructions. A total of five mice were used for each group per experiment.

Statistical analysis. Statistical analysis was performed using SPSS 18.0 software (SPSS Inc., Chicago, IL, USA). Data were analyzed using one-way analysis of variance, followed by a least significant difference test. $\mathrm{P}<0.05$ (two-tailed test) was considered to indicate a statistically significant difference. The results are expressed as the mean \pm standard deviation, unless otherwise stated.

\section{Results}

siRNA effectively inhibits the expression of TLR2. To investigate whether TLR2-specific siRNA silenced the expression of TLR2 in the present study, the mRNA expression levels of TLR2 were detected using RT-qPCR. The mRNA expression levels of TLR2 were downregulated in the TLR2-specific siRNA group $72 \mathrm{~h}$ post-transfection, compared with the control group (Fig. 1A and B). This indicated that TLR2-specific
siRNA effectively inhibited the gene expression of TLR2. Western blot analysis demonstrated that TLR2-specific siRNA effectively inhibited the protein expression levels of TLR2 $72 \mathrm{~h}$ post-transfection in the TLR2 siRNA group, compared with the control group (Fig. 1C and D). These results suggested a significant reduction in the expression of TLR2 in the TLR2-siRNA group, compared with the other groups.

HDM upregulates the expression of CD117 in DCs. To investigate whether HDM activated the expression of c-kit in DCs in the present study, CD117 surface molecules were detected using flow cytometry. HDM upregulated the expression of CD117 on the surface of DCs, compared with the control group (Fig. 2A-C). This confirmed that HDM effectively activated the gene expression of c-kit in the DCs.

TLR2 siRNA downregulates the expression of CD117 in DCs. CD117, which is a receptor for SCF, is associated with the expression of c-kit. To investigate whether TLR2-specific siRNA inhibited the expression of c-kit, the expression of CD117 on the surface of the DCs was analyzed using flow cytometry. TLR2 siRNA inhibited the expression of CD117 on the surface of the DCs, compared with the control group (Fig. 2D-F).

TLR2 siRNA reduces the expression of $c$-kit. To investigate whether TLR2-specific siRNA affected the expression levels of c-kit, the mRNA levels of c-kit were detected using RT-qPCR, and the protein levels of c-kit were detected using western blot analysis. The mRNA and protein expression levels of c-kit 
A

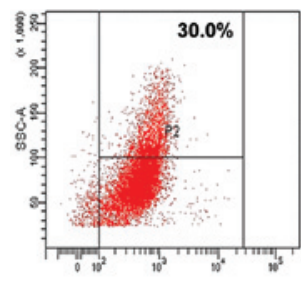

D

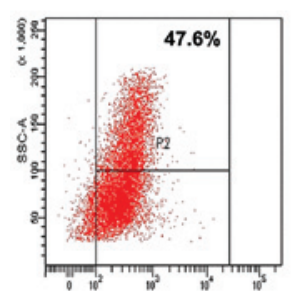

B

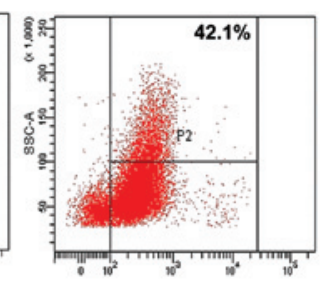

$\mathbf{E}$

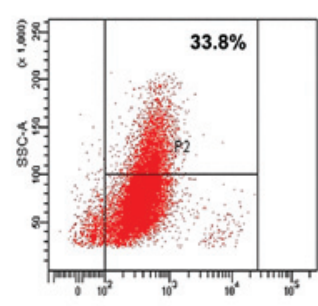

C

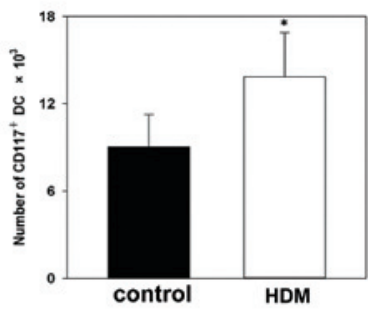

F

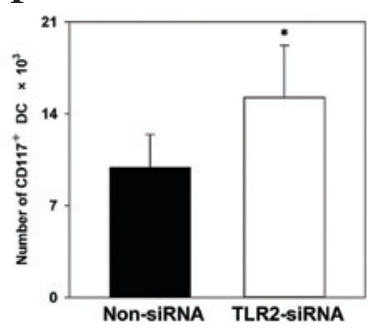

Figure 2. Representative analysis of CD117 in DCs by flow cytometry. (A) Number of CD117 $7^{+}$Cs accounted for $30 \%$ of cells in the control group, which was not treated with HDM allergen. (B) Number of CD117 $7^{+}$Cs was $42.1 \%$ in the experimental group $72 \mathrm{~h}$ post-HDM administration. (C) Data are presented as the mean $\pm \mathrm{SM}$ of the number of CD117 DCs. HDM activated the expression of c-kit in the DCs. (D) Number of CD117 DCs was $47.6 \%$ in the group $72 \mathrm{~h}$ post-HDM administration. (E) Number of CD117 DCs was $33.8 \%$ in the group that was pre-treated with HDM for $72 \mathrm{~h}$, followed by transfection with TLR2 siRNA for $72 \mathrm{~h}$. (F) Data are presented as the mean \pm SD of the number of CD117 DCs. The results demonstrated that TLR2-siRNA inhibited the expression of CD117 in the DCs. " $\mathrm{P}<0.05$, vs. control group. The experiment was performed three times and representative results are presented. TLR2, Toll-like receptor; DCs, dendritic cells; siRNA, small interfering RNA; SD, standard deviation.

A

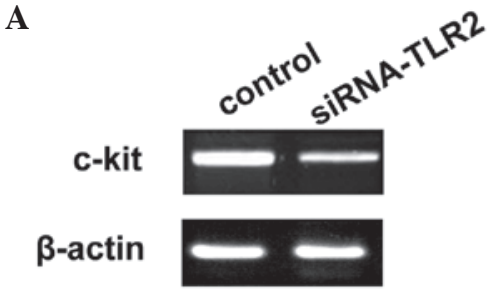

C

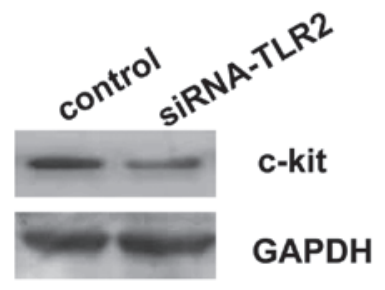

B

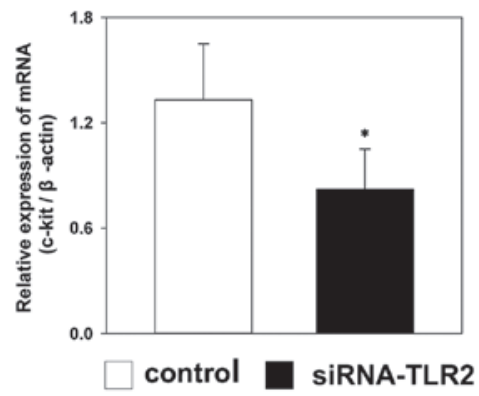

D

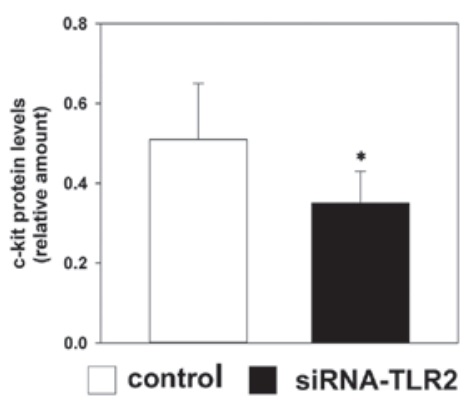

Figure 3. Analysis of the mRNA and protein expression levels of c-kit in DCs. (A) mRNA expression of c-kit was downregulated $72 \mathrm{~h}$ post-transfection with TLR2 siRNA. (B) Data are presented as the mean \pm SD of the relative intensity of c-kit normalized against $\beta$-actin. (C) Protein expression of $\mathrm{c}-\mathrm{kit}$ in DCs $72 \mathrm{~h}$ post-transfection. (D) Data are presented as the mean \pm SD of the relative intensity of c-kit normalized against GAPDH. DCs were collected $72 \mathrm{~h}$ post-transfection with TLR2 siRNA or phosphate-buffered saline vehicle. ${ }^{*} \mathrm{P}<0.0$, vs. control group. The experiment was performed three times and representative results are presented. TLR2, Toll-like receptor; DCs, dendritic cells; siRNA, small interfering RNA; SD, standard deviation.

were downregulated in the TLR2-siRNA group $72 \mathrm{~h}$ following transfection, compared with the control group. There was a significant difference in the expression levels of c-kit between the TLR2-siRNA group and the control group (Fig. 3).

Western blot analysis indicates that TLR2-siRNA inhibits the expression of CD80 and CD86. CD80/CD86 are important co-stimulatory molecules between DCs and T-cells, which are important in the differentiation and activation of Th2 (15). In the present study, TLR2-siRNA effectively inhibited the expression levels of CD80 and CD86 $72 \mathrm{~h}$ following transfection in the TLR2-siRNA group, compared with the control group (Fig. 4).

TLR2-siRNA regulates the production of cytokines. The concentration of IL- 6 in the culture supernatants of the DCs decreased more markedly in the TLR2-siRNA group, compared 
A

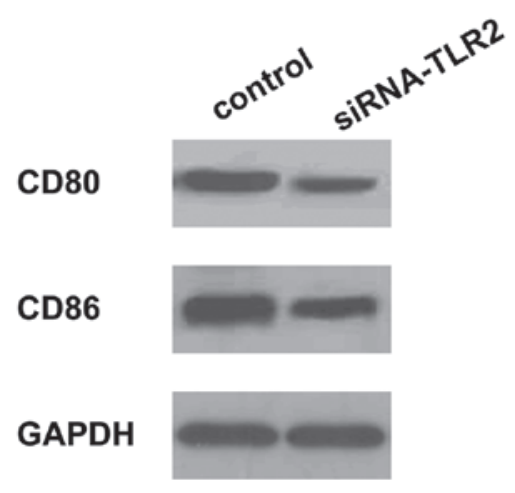

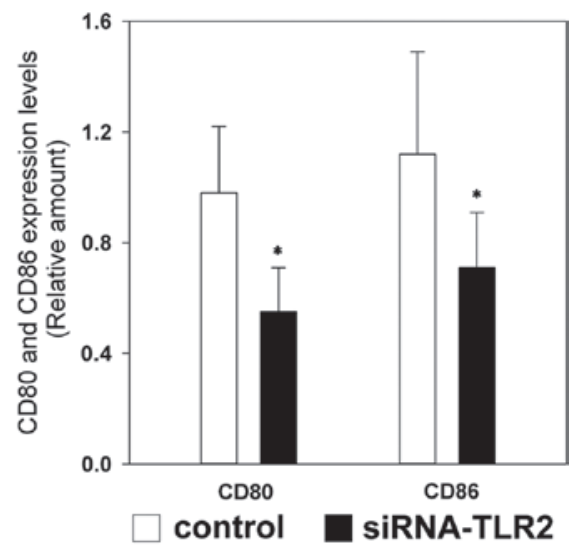

Figure 4. TLR2-siRNA inhibits the expression of CD80 and CD86. (A) Protein expression levels of CD80 and CD86 in DCs. (B) Data are presented as the mean \pm standard deviation of the relative levels of CD80 and CD86 normalized against GAPDH. DCs were collected $72 \mathrm{~h}$ post-transfection with TLR2 siRNA or phosphate-buffered saline. "P<0.05, vs. control group. The experiment was performed three times, with representative results presented. TLR2, Toll-like receptor; DCs, dendritic cells; siRNA, small interfering RNA.

A

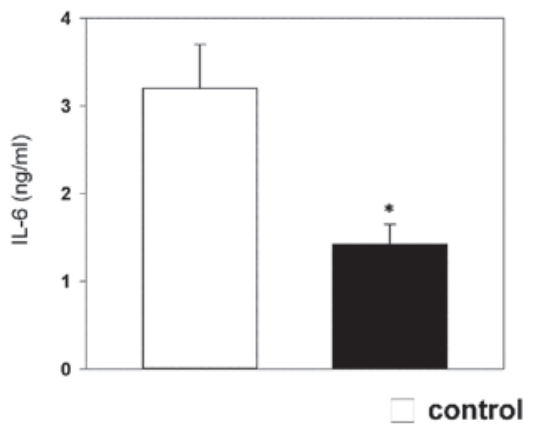

B

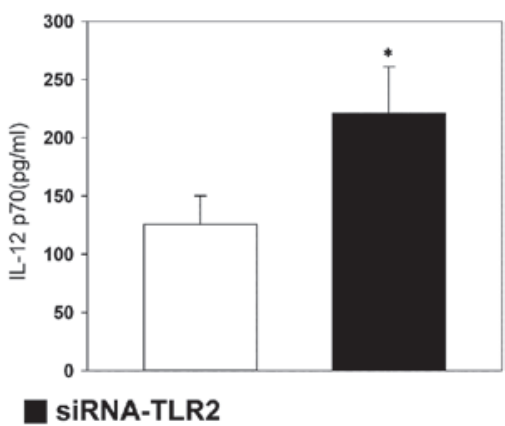

Figure 5. TLR2 siRNA selectively regulates cytokine production in DCs. The levels of (A) (IL)-6 and (B) IL-12 in the supernatants of the DCs were measured using ELISA analysis. The supernatants were obtained $72 \mathrm{~h}$ post-transfection with the TLR 2 siRNA or a phosphate-buffered saline vehicle. ${ }^{*} \mathrm{P}<0.05$, vs. control (Student's t-test). Data are presented as the mean \pm standard error of the mean of three independent experiments. TLR2, Toll-like receptor; DCs, dendritic cells; siRNA, small interfering RNA; IL, interleukin.

with the control group (Fig. 5A). By contrast, the production of IL-12 was markedly increased in the TLR2-siRNA group, compared with the control group (Fig. 5B).

\section{Discussion}

In the present study, specific siRNA was used to silence the expression of TLR2. Silencing of TLR2 was found to downregulate the expression of CD117 on the surface of DCs. In addition, it decreased the transcription and translation of c-kit, a proto-oncogene that encodes a tyrosine kinase receptor. $\mathrm{CD} 117$ is the expression product of c-kit and is a member of the platelet-derived growth factor family of tyrosine kinase receptors, which binds to the SCF ligand. Numerous studies have been performed to investigate the role of c-kit in the development of asthma, and have indicated that c-kit/SCF is closely associated with mast cell and eosinophil infiltration of the airways, and the promotion of mast cell degranulation $(16,17)$.

Pathogen recognition is mediated by a set of germline-encoded receptors, which are termed pattern-recognition receptors (PRRs). TLRs are mammalian PRRs, which are important in the recognition of microbial components, and HDM allergens can be recognized by TLRs. A previous study suggested that c-kit in DCs may be activated by HDM allergens, regulate T-helper cell differentiation and induce the inflammatory response in experimental allergic mice (10). Redecke et al (18) also demonstrated that activation of TLR2 induces a Th2 immune response and promotes the presentation of experimental asthma; however, the underlying molecular mechanism remains to be elucidated. In the present study, specific siRNA inhibition of TRL2 resulted in a significant decrease in the transcription and expression of c-kit in DCs. In addition, HDM upregulated the expression of CD117 on the surface of DCs. These results indicated that activation of TLR2 may be correlated with the functioning of c-kit, therefore it can be concluded that there is a HDM-TLR2-c-kit pathway, which induces Th2 activation in response to HDM. More TLR2 and TLR4 are expressed on the surface of DCs, compared with other TLRs (19). Previous studies have reported that TLR4 signaling in lung DCs is required for the induction of Th1 responses, but is not essential for the induction of Th2 responses (20-22).

Co-stimulatory molecules between DCs and T-cells, including CD80 (B7-1)/CD86 (B7-2) and CD28, are crucial in the differentiation of naive CD4 T-cells, which appears to be one of the initial steps in airway sensitization, ultimately leading to the generation of a Th2-type immune response $(23,24)$. In the present study, a specific siRNA was used to inhibit the expression of TLR2. Knockdown of TLR2 effectively downregulated 
the expression of CD80 and CD86 in the experimental group, compared with the control group. These results demonstrated that activation of TRL2 promoted the expression levels of CD80 and CD86 on the surface of DCs, inducting the activation and differentiation of naive CD4 T-cells. It can, therefore, be inferred that DCs initially bind to HDM allergens through TLR2 and present the allergen to Th 2 cells, resulting in Th 2 cell activation via co-stimulatory molecules. Activated Th2 cells produce various cytokines, including IL-4, IL-5, IL-13 and GM-CSF, which are essential in the pathogenesis of asthma by promoting the survival and recruitment of eosinophils and mast cells (25).

In the present study, by inhibiting the expression of TLR2 through specific siRNA, the activated DCs produced less IL-6 and more IL-12. Furthermore, these alterations in cytokine production were associated with the downregulation of c-kit. Notably, a previous study demonstrated that direct inhibition of TLR 2 results in the production of IL-12 in macrophages by interfering with JNK (26). In addition, IL-6 has been associated with Th2 and Th17 differentiation (27), and DC production of IL-6 has induces Th-cell differentiation toward the Th2 cell phenotype. By contrast, IL-12 steers $\mathrm{CD} 4^{+} \mathrm{T}$-cell responses toward a Th1 phenotype by inducing the production of interferon- $\gamma$ in naive Th-cells (28-30). Several signaling pathways, including the Ras/extracellular signal-regulated kinase, phosphatidylinositol 3-kinase (PI3K), phospholipase C and D, Src kinase and janus kinase/signal transducer and activator of transcription pathways are activated downstream of c-kit following ligand binding $(31,32)$. The c-kit/PI3K signaling axis positively regulates the production of IL- 6 . In addition, c-kit is associated with Th2 responses through the Notch ligand Jagged-2 signaling pathway $(9,33)$. Overexpression of IL-12 in DCs significantly decreases Th2 sensitization to inhaled antigens and eosinophilic airway inflammation by skewing the response towards strong Th1 immunity $(29,34)$. Furthermore, previous studies have demonstrated that IL-12 is more suitable in reducing the infiltration of inflammatory cells and inhibiting inflammatory response in allergic asthma $(35,36)$. However, endogenous IL-12 contributes to the recruitment of eosinophils into the airways, as observed in asthma, possibly via enhancement of the expression of vascular cell adhesion molecule-1 (37). Since the complex signal transduction pathways ultimately result in the same cytokine performing distinct functions in the development of asthma, clarification of the pathogenesis of asthma is difficult.

In conclusion, the results of the present study demonstrated that TLR2 is important in the activation of c-kit in DCs. Inhibiting the expression of TRL2 with specific siRNA resulted in the downregulation of co-stimulatory molecules (B7), reduced expression of IL-6 and increased expression of IL-12. These effects were associated with the development of allergic asthma; however, the involvement of other TLRs in the activation of c-kit in DCs remains to be elucidated. Further investigations are required to understand the role of TLRs in the development of asthma.

\section{Acknowledgements}

The present study was supported by grants from The Nature Science Foundation of The Education Department of Shaanxi Provincial Government (grant. no. 11JK0662), and the Innovation and Entrepreneurship Training Project of University Student in Shaanxi Province (grant no. 20131741).

\section{References}

1. Roche N, Chinet TC and Huchon GJ: Allergic and nonallergic interactions between house dust mite allergens and airway mucosa. Eur Respir J 10: 719-726, 1997.

2. Edling CE and Hallberg B: c-Kit - a hematopoietic cell essential receptor tyrosine kinase. Int J Biochem Cell Biol 39: 1995-1998, 2007.

3. Lukacs NW, Strieter RM, Lincoln PM, Brownell E, Pullen DM, Schock HJ, Chensue SW, Taub DD and Kunkel SL: Stem cell factor (c-kit ligand) influences eosinophil recruitment and histamine levels in allergic airway inflammation. J Immunol 156: 3945-3951, 1996.

4. Lukacs NW, Kunkel SL, Strieter RM, Evanoff HL, Kunkel RG, Key ML and Taub DD: The role of stem cell factor (c-kit ligand) and inflammatory cytokines in pulmonary mast cell activation. Blood 87: 2262-2268, 1996.

5. Platt-Mills TA, Sporik RB, Chapman MD and Heymann PW: The role of indoor allergens in asthma. Allergy 50 (22 Suppl): $5-12,1995$

6. Platts-Mills TA, Vervloet D, Thomas WR, Aalberse RC and Chapman MD: Indoor allergens and asthma: Report of the Third International Workshop. J Allergy Clin Immunol 100: S2-S24, 1997.

7. Redecke V, Häcker H, Datta SK, Fermin A, Pitha PM, Broide DH and Raz E: Activation of Toll-like receptor 2 induces a Th2 immune response and promotes experimental asthma. J Immunol 172: 2739-2743, 2004.

8. Hammad H and Lambrecht BN: Dendritic cells and epithelial cells: Linking innate and adaptive immunity in asthma. Nat Rev Immunol 8: 193-204, 2008.

9. Redecke V, Häcker H, Datta SK, Fermin A, Pitha PM, Broide DH and Raz E: Cutting edge: Activation of Toll-like receptor 2 induces a Th2 immune response and promotes experimental asthma. J Immunol 172: 2739-2743, 2004.

10. Krishnamoorthy N, Oriss TB, Paglia M, Fei M, Yarlagadda M, Vanhaesebroeck B, Ray A and Ray P: Activation of c-Kit in dendritic cells regulates T helper cell differentiation and allergic asthma. Nat Med 14: 565-573, 2008.

11. Min WP, Gorczynski R, Huang XY, Kushida M,Kim P,Obataki M, Lei J, Suri RM and Cattral MS: Dendritic cells genetically engineered to express Fas ligand induce donor-specific hyporesponsiveness and prolong allograft survival. J Immunol 164: 161-167, 2000.

12. Lutz MB, Kukutsch N, Ogilvie AL, Rössner S, Koch F, Romani N and Schuler G: An advanced culture method for generating large quantities of highly pure dendritic cells from mouse bone marrow. J Immunol Methods 223: 77-92, 1999.

13. Zheng X, Vladau C, Zhang X, Suzuki M, Ichim TE, Zhang ZX, Li M, Carrier E, Garcia B, Jevnikar AM and Min WP: A novel in vivo siRNA delivery system specifically targeting dendritic cells and silencing CD40 genes for immunomodulation. Blood 113: 2646-2654, 2009.

14. Livak KJ and Schmittgen TD: Analysis of relative gene expression data using real-time quantitative PCR and the 2(-Delta Delta C(T)) Method. Methods 25: 402-408, 2001.

15. Tsuyuki S, Tsuyuki J, Einsle K, Kopf M and Coyle AJ: Costimulation through B7-2 (CD86) is required for the induction of a lung mucosal $\mathrm{T}$ helper cell 2 (TH2) immune response and altered airway responsiveness. J Exp Med 185: 1671-1680, 1997.

16. Ito T, Smrž D, Jung MY, Bandara G, Desai A, Smržová Š, Kuehn HS, Beaven MA, Metcalfe DD and Gilfillan AM: Stem cell factor programs the mast cell activation phenotype. J Immunol 188: 5428-5437, 2012.

17. Columbo M, Horowitz EM, Botana LM, MacGlashan DW Jr, Bochner BS, Gillis S, Zsebo KM, Galli SJ and Lichtenstein LM: The human recombinant c-kit receptor ligand, rhSCF, induces mediator release from human cutaneous mast cells and enhances IgE-dependent mediator release from both skin mast cells and peripheral blood basophils. J Immunol 149: 599-608, 1992.

18. Redecke V, Häcker H, Datta SK, Fermin A, Pitha PM, Broide DH and Raz E: Cutting edge: Activation of toll-like receptor 2 induces a Th2 immune response and promotes experimental asthma. J Immunol 172: 2739- 2743, 2004. 
19. Werling D, Hope JC, Howard CJ and Jungi TW: Differential production of cytokines, reactive oxygen and nitrogen by bovine macrophages and dendritic cells stimulated with Toll-like receptor agonists. Immunology 111: 41-52, 2004.

20. Agrawal S, Agrawal A, Doughty B, Gerwitz A, Blenis J, Van Dyke T and Pulendran B: Cutting edge: Different Toll-like receptor agonists instruct dendritic cells to induce distinct Th responses via differential modulation of extracellular signal-regulated kinase-mitogen-activated protein kinase and c-Fos. J Immunol 171: 4984-4989, 2003.

21. Boonstra A, Asselin-Paturel C, Gilliet M, Crain C, Trinchieri G, Liu YJ and O'Garra A: Flexibility of mouse classical and plasmacytoid-derived dendritic cells in directing $\mathrm{T}$ helper type 1 and 2 cell development: Dependency on antigen dose and differential Toll-like receptor ligation. J Exp Med 197: 101-109, 2003.

22. Byun EH, Kim WS, Kim JS, Won CJ, Choi HG, Kim HJ, Cho SN Lee K, Zhang T, Hur GM and Shin SJ: Mycobacterium paratuberculosis CobT activates dendritic cells via engagement of Toll-like receptor 4 resulting in Th1 cell expansion. J Biol Chem 287: 38609-38624, 2012.

23. Haczku A, Takeda K, Redai I, Hamelmann E, Cieslewicz G, Joetham A, Loader J, Lee JJ, Irvin C and Gelfand EW: Anti-CD86 (B7.2) treatment abolishes allergic airway hyperresponsiveness in mice. Am J Respir Crit Care Med 159: 1638-1643, 1999

24. Mathur M, Herrmann K, Qin Y, Gulmen F, Li X, Krimins R, Weinstock J, Elliott D, Bluestone JA and Padrid P: CD28 interactions with either CD80 or CD86 are sufficient to induce allergic airway inflammation in mice. Am J Respir Cell Mol Biol 21: 498-509, 1999.

25. Hammad H and Lambrecht BN: Dendritic cells and epithelial cells: Linking innate and adaptive immunity in asthma. Nat Rev Immunol 8: 193-204, 2008.

26. Wang S, Chen Z, Hu C, Qian F, Cheng Y, Wu M, Shi B, Chen J, Hu Y and Yuan Z: Hepatitis B virus surface antigen selectively inhibits TLR2 ligand-Induced IL-12 production in monocytes/macrophages by interfering with JNK activation. J Immunol 190: 5142-5151, 2013.

27. Dodge IL, Carr MW, Cernadas M and Brenner MB: IL-6 production by pulmonary dendritic cells impedes Th1 immune responses. J Immunol 170: 4457-4464, 2003.
28. Kuipers H, Hijdra D, De Vries VC, Hammad H, Prins JB, Coyle AJ, Hoogsteden $\mathrm{HC}$ and Lambrecht BN: Lipopolysaccharide-induced suppression of airway Th2 responses does not require IL-12 production by dendritic cells. J Immunol 171: 3645-3654, 2003.

29. Bilenki L, Gao X, Wang S, Yang J,Fan Y, Han X, Qiu H and Yang X: Dendritic cells from mycobacteria-infected mice inhibits established allergic airway inflammatory responses to ragweed via IL-10- and IL-12-secreting mechanisms. J Immunol 184: 7288-7296, 2010.

30. Kuipers H, Heirman C, Hijdra D, Muskens F, Willart M, van Meirvenne S, Thielemans K, Hoogsteden HC and Lambrecht BN: Dendritic cells retrovirally overexpressing IL-12 induce strong Th1 responses to inhaled antigen in the lung but fail to revert established Th2 sensitization. J Leukoc Biol 76: 1028-1038, 2004.

31. Dabbagh K, Takeyama K, Lee HM, Ueki IF, Lausier JA and Nadel JA: IL-4 induces mucin gene expression and goblet cell metaplasia in vitro and in vivo. J Immunol 162: 6233-6237, 1999.

32. Lennartsson J, Jelacic T, Linnekin D and Shivakrupa R: Normal and oncogenic forms of the receptor tyrosine kinase kit. Stem Cells 23: 16-43, 2005

33. Amsen D, Blander JM,Lee GR, Tanigaki K, Honjo T and Flavell RA: Instruction of distinct CD4 T helper cell fates by different notch ligands on antigen-presenting cells. Cell 117: 515-526, 2004.

34. Hofstra CL, Van Ark I, Hofman G, Kool M, Nijkamp FP and Van Oosterhout AJ: Prevention of Th2-like cell responses by coadministration of IL-12 and IL-18 is associated with inhibition of antigen-induced airway hyperresponsiveness, eosinophilia, and serum IgE levels. J Immunol 161: 5054-5060, 1998.

35. Wang S, Fan Y, Han X, Yang J, Bilenki L and Yang X: IL-12-dependent vascular cell adhesion molecule-1 expression contributes to airway eosinophilic Inflammation in a mouse model of asthma-like reaction. J Immunol 166: 2741-2749, 2001.

36. van der Pouw Kraan TC, Boeije LC, de Groot ER, Stapel SO, Snijders A, Kapsenberg ML, van der Zee JS and Aarden LA: Reduced production of IL-12 and IL-12-dependent IFN-gamma release in patients with allergic asthma. J Immunol 158: 5560-5565, 1997.

37. Kuipers H, Hijdra D, De Vries VC, Hammad H, Prins JB, Coyle AJ, Hoogsteden HC and Lambrecht BN: Lipopolysaccharide-induced suppression of airway Th2 responses does not require IL-12 production by dendritic cells. J Immunol 171: 3645-3654, 2003. 